\title{
Collage as a Pedagogical Practice to Support Teacher Candidate Reflection
}

\author{
Gail Prasad and The Lions BEd Group
}

\begin{abstract}
This article reports on collage as a pedagogical practice to support teacher candidate reflection. We outline a multi-step collage-based reflection workshop that was part of a required course on "Inquiries Into Learning." The summative collage project was designed to help teacher candidates reflect on their vision of learning (hope) and their fears and doubts as beginning teachers. The process and product of their final integrated collage led students to interrogate how their hopes and fears mingle together in practice. Six teacher candidates share their series of collages and GIFs, along with their reflective personal statements. We conclude by highlighting lessons learned through collaging from the perspective of students.
\end{abstract}

"While we cannot learn or be taught to think, we do have to learn how to think well, especially how to acquire the general habits of reflecting." (Dewey, 1933, p. 35)

Reflective practice (Dewey, 1933) is a fundamental pillar of many university-based teacher training programs. In Canada, the Ontario College of Teachers includes "reflection" under its "Professional Practice" standard necessary for all teachers. Academic journals, books, and conferences have been devoted to the topic of how to foster teacher candidates' critical reflection about their developing teaching practice. Even so, in my work as a university-based teacher educator, it has not been uncommon to observe what I have come to call "reflection-fatigue" on the part of preservice teacher candidates. Across their multiple university-based courses, as well as their school and community based practica, teacher candidates are called upon to reflect on action and to reflect in action (Schön, 1983). Nonetheless, requiring teacher candidates to engage in reflection about their experiences in the classroom during student teaching, does not guarantee that they will realize the benefits of reflecting on their practice (Zeichner \& Lui, 2010).

In haste to check off all the boxes necessary to become a certified teacher, I often worry that reflecting on practice for teacher candidates becomes reduced to going through the motions of posting the required 300 words to an online discussion forum or to an e-portfolio, sometimes along with an artifact from their teaching. As one teacher candidate recently put it, "If there's one thing this [teacher education] program is big on, it's reflection. In all honesty, I am tired of writing reflections and I don't see much value in being graded on how I think/feel/challenge an experience that I have had." Both the intense pace of teacher education programs and the tyranny of grades are at odds with cultivating a culture of unhurried, honest, and heartfelt reflection. As I see students struggle to keep up with the demands of course work and practice teaching, I wonder how by doing less, we might actually support our teacher candidates in coming to know more-more of who they are, who their students are and who they can become together. 
Over the past two decades as a classroom teacher, teacher educator, and classroom-based researcher, I have returned time and again to the question: how do we sustain teacher candidate reflection about themselves as teachers, their learners, and the systems of power they work within as agents of transformation? How can I help teacher candidates be(come) mindful of the ways their intersectional identities shape their teaching and learning? How, through my pedagogical design, can I create space both for listening and for dialogue with self and with others? Ultimately, the purpose of reflection is to lead to transformative action.

In an effort to show, rather than tell, in this article, I begin briefly with a discussion of how I have come to incorporate collage as a pedagogical practice to support teacher candidate reflection. Next, I outline the design of a multi-step summative collage-based reflection as a summative project for a required firstyear teacher education course on "Inquiries Into Learning." Six preservice candidates then share their collages and accompanying personal statements with their own voices. Finally, drawing from both teacher candidates' reflections about both the process and products of their collaging, I conclude by articulating affordances and challenges of using arts-informed reflection within the context of teacher education programs.

\section{Coming to Collage: From Research Method to Pedagogical Practice}

Arts-based research (ABR) in education (Butler-Kisber, 2010, 2018; Cahnmann-Taylor \& Seigesmund, 2017; Cole \& Knowles, 2008) and arts-integration in teaching and learning (Wiebe et al., 2007) have both gained increasing attention in the 21 st century, particularly as a way of amplifying voices and perspectives of minoritized communities (Robinson, 2013). During my doctoral research about children's social representations of plurilingualism (Prasad, 2015), collage as a research method supported my young coresearchers to make visible their complex and plural understandings of the linguistic diversity that permeated their lives. As part of my preparation to engage children in collage as a research method, I spent two years taking group classes with Donnelly Smallwood, a professional teaching-artist with a focus in collage, as well as individualized directed studio exploration under her guidance at a local art school. Although, at the outset, I was apprehensive to see myself as "artist," I came to relish the time I spent in exchanges with my fellow classmates, in dialogue with Smallwood and in studio. I eventually came to see that

when I relax into the creative process of gathering, layering, (re)combining and juxtaposing images, I am able to make new connections and allow ideas to surface that are substantively different than when I try to make sense cognitively of multiple pieces of information in the classroom or ... in my office. Rather than my head guiding my hand about what it should write, when I collage, the directionality of my thinking moves up first from my sensing of the materials in my hands as a I rearrange images, cut away parts or cover up pieces, up through my eyes as I begin to see new ideas, patterns and possibilities take shape, and then connect them in my mind and heart to what the composition reveals. (Prasad, 2015, p. 7)

The creative process involved in collaging is a centering one. Collaging invites us to enter into a state of flow (Csikszentmihalyi, 1975) that connects our inner compass to the outer world. Whereas academic training and research privileges critical reasoning and cognitive ways of knowing, I have found that 
creativity can temper criticality to produce clarity of mind and to open up alternative ways of knowing, doing and be(com)ing. As Bresler (2018) puts it, aesthetic-based research pedagogies function as internal compasses that enable us "to tune in to what [we] study and in to [ourselves] through attentive observations and opening a dialogue between what is encountered and oneself" (p. 654). Attentive observation and inner dialogue are difficult to teach as discrete skills because they are embodied and are cultivated with care over time. They require a consciousness awareness, and at times a reckoning with self that can be uncomfortable.

I have increasingly incorporated collage as reflection into my teaching, particularly with preservice teacher candidates because the process and its products necessarily require students to slow down so that they can see and listen. Searching existing images for resonance and dissonance helps focus one's attention and the sensory processes of cutting, layering, and gluing necessarily slows us down. Following each iteration of a collage-based reflection that I have facilitated as part of my teacher education courses over the past decade, I have had students report anecdotally that the experience was one of the most meaningful and memorable parts of their journeys towards becoming teachers. Many adults, particularly those who do not identify themselves as "creative-types," can find many art forms daunting (drawing, painting, sculpting, dancing, theatre) because they do not feel they have the necessary skills or talent to engage in the creative process with confidence. Collage, however, is an accessible form because it relies on basic skills - cutting and pasting - that are generally mastered in childhood (Butler-Kisber, 2010, 2018). The collage, personal statements, and students' perspectives on their experience collaging that are presented in the remainder of this article build a case for the powerful possibility for collage as a reflective practice and pedagogy in teacher education.

\section{Course Description and Assignment}

In January 2020, I was assigned to teach, "Inquiries Into Learning," for first-year teacher candidates. This course is a requirement for all teacher candidates as part of a two-year Bachelor of Education program at a major university in Ontario, Canada. The course considers how diverse theoretical lenses shape our understandings of ourselves and others as teachers and as learners, conditions for teaching and learning, and the imperatives of institutions and communities. Each week, students engaged in whole class and small group discussions with their colleagues about the different intersectional lenses through which we might see ourselves and our students, including, but not limited to, race, class, gender, language, and ability. Throughout the term, students were expected to submit critical written reflections in response to readings and in-class discussions. The summative project for the course was designed to invite students to temper the critical work we had done throughout the semester with creative reflection, by participating in a three-week collage workshop to produce a series of collages in response to the following three Big Questions:

1) A Hope Collage: What vision of learning do you want to reflect and project for your future learners?

2) A Fear Collage: What fears, doubts and/or questions are you wrestling with regarding teaching and learning with learners in your future classroom? 
3) An Integrated Collage: How do you negotiate your hope-filled vision of teaching and learning with your inner thoughts and dialogue with your fears, doubts, and questions about yourself and your future students?

During our in-class workshop, I encouraged students to bring in found print materials, as well as scissors and glue. I also provided a range of magazines and other print materials that students could use as source material. I had prepared materials by cutting magazine pages with images out from a range of magazines such as National Geographic, Architectural Digest, Fine Gardens, and Birds \& Blooms. I selected magazine images that did not include well-known personalities and public figures, and I removed pages from magazines so students would not get distracted with reading the magazines. I also discouraged students from using words in their collages, because I wanted them to focus on connecting to images, rather than reading text as their primary mode of entering into meaning making through collage. (Many students still chose, however, to incorporate words and phrases.) I colour photocopied magazine pages so that every group of students would have a stack of images to choose from in addition to any of their own materials. As a result, there was a repetition of some images throughout students' final collages.

In this workshop, I walked students through the process of selecting images that resonated (or not) with them in response to the big question posed for each collage. I also modelled techniques for cutting, layering, and gluing images down on the circle templates provided for each collage. In order to flatten the seams between images in each collage, we scanned the finished hope collages in colour (Figure 1) and the finished doubt collages in black and white (Figure 2).

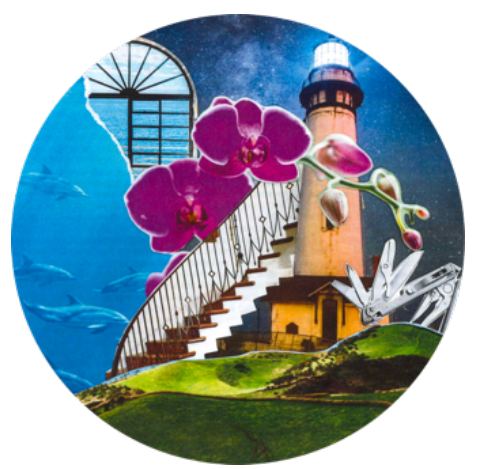

Fig. 1: Hope collage, full colour

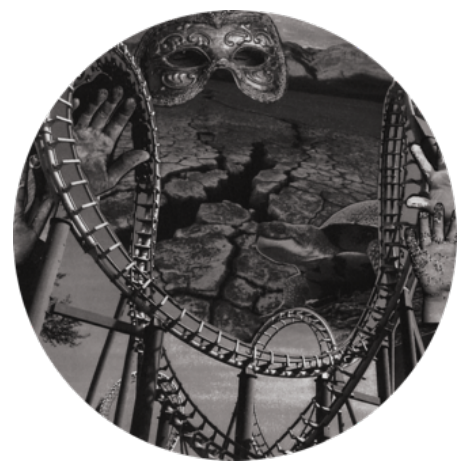

Fig. 2: Doubt collage, black and white 
I then introduced three different techniques for integrating the hope and doubt collages into one final collage: tearing, cutting, and weaving (Figure 3).

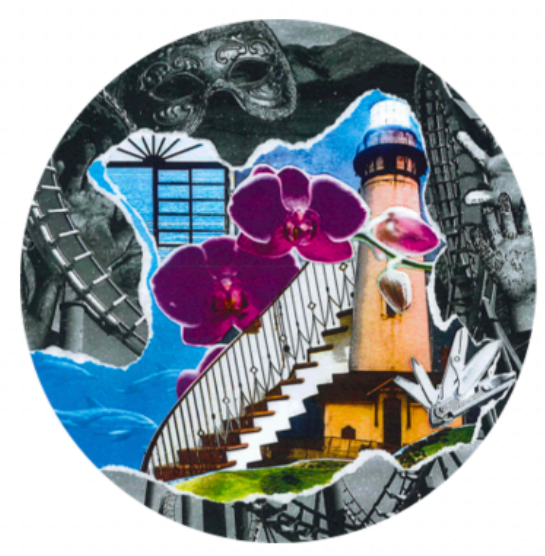

TEAR

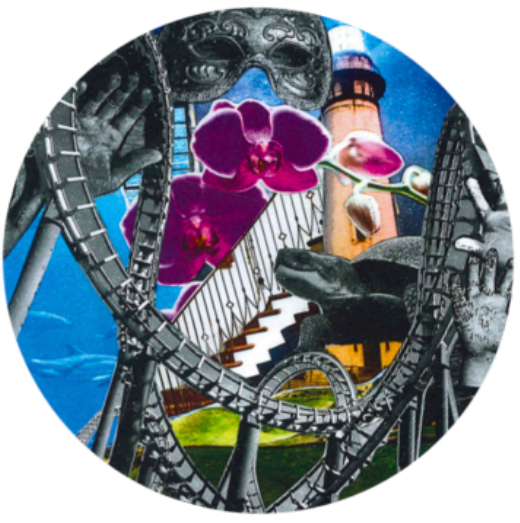

CUT

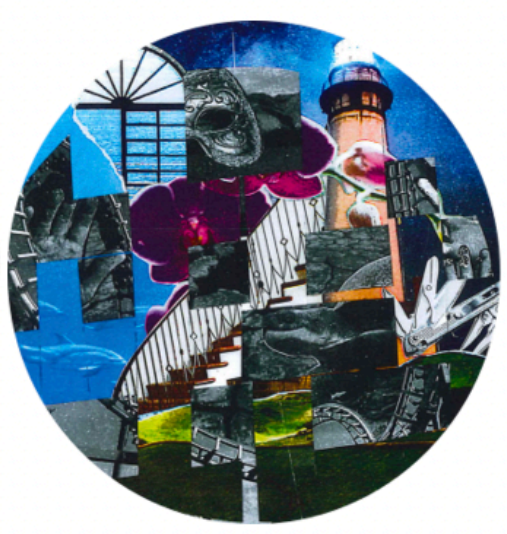

WEAVE

Fig. 3: Three techniques to integrate hope and fear collages

The final integrated collage was designed to help teacher candidates see-literally and figuratively-how hope and fear are not necessarily in conflict with one another, but rather, that we live continually within the tension between them. In addition to the collage protocols, students were asked to use the images in their collages as metaphors and the following narrative protocol as a scaffold for composing a final reflective personal statement (Figure 4).

\title{
[Collage Title] By [name]
}

\section{Learning can be as ...}

Learning is like...

As a beginning teacher, I sometimes feel like...

I often question...

\author{
[Collage Title] reflects how I feel ... / how I think about... \\ Through the process of collage, I have come to see ...
}

Fig. 4: Personal statement reflection protocol 
Before turning to teacher candidates' collages and statements, it should be noted that, although I had scheduled for this multi-step collage workshop to take place over three weeks of face-to-face classes, we had to pivot to remote learning following the first in-class session (three hours) due to COVID-19. While less than ideal, I produced several short videos and outlined the collage process on our course site in our learning management system. Students were also given the option of combining their collages into GIFs, if they were unable to scan and print their hope and doubt collages. In several cases, students created alternating GIFs with their hope and fear collages as a form of virtual integration.

I created a sample GIF using my own Hope and Fear collages (Figure 5) using the following free GIF maker: https://imgflip.com/gif-maker.

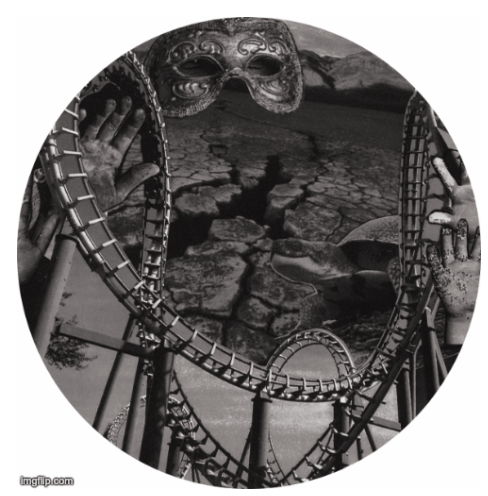

Fig. 5: Ever unfinished GIF (https://imgflip.com/gif/3smhci)

I invited the following six students to contribute their collages and personal statements to illustrate collage as a hands-on pedagogical practice for reflection, even in the midst of pandemic times, when teaching and learning as we have known them, have been completely disrupted. We have included the hope (left) and fear (right) collages in colour and black and white respectively. The integrated collage is centred. The first three students each used different strategies for integrating their hope and fear collages. The last three students created alternating GIFs with their hope and fear collages. Accompanied by students' personal statements, the collages illustrate the range of ways that students engaged in reflecting on their hopes and fears, while also coming to see how they animate one another. 


\section{Collage as Critical and Creative Reflection: Six Examples}

\section{Lifelong Learner by Pat Baybayan}
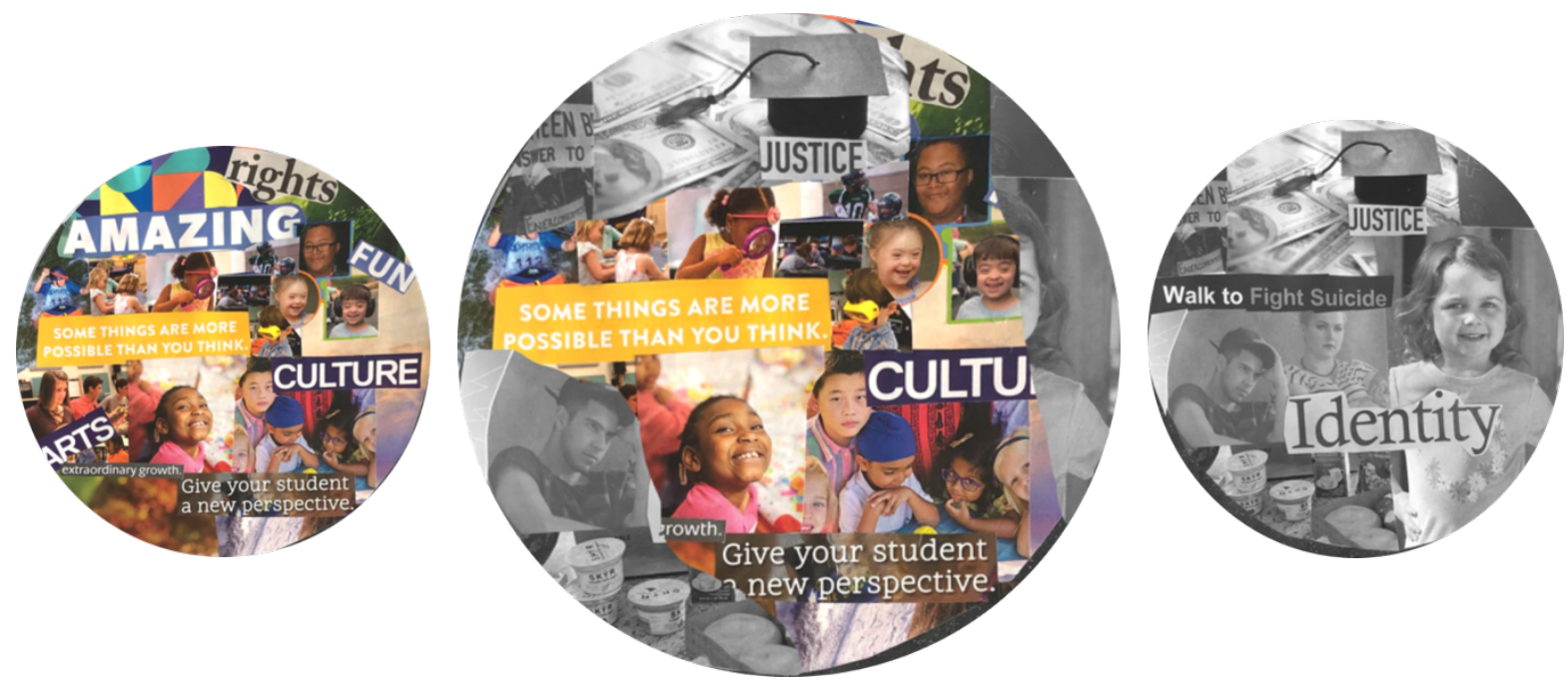

Fig. 6: Lifelong Learner collage series by Pat Baybayan

Learning can be as fun as a game. Just like a game, learning should keep everyone engaged and on their feet. Students or players should be able to work together, but also be able to make meaning out of their individual experiences. Even though games and learning may feel competitive at times, at the end of the day, it should be enjoyable, fair, and accessible to everyone.

Learning is like riding a bicycle up a steep hill. Unless you keep cycling, you'll fall back down the hill. Students and teachers alike should aspire to be lifelong learners. After all, a big part of life is to learn, not solely in the classroom but also through obstacles, successes, relationships, experiences, and so forth.

As a beginning teacher, I sometimes feel like I stand in a grey area between students and teachers. On one hand, I'm open to learning from teachers who have lived through the obstacles of the teaching profession and have wisdom to offer. On the other hand, I stand for the changes that need to be made that are in the greater interest of the students. I often struggle with these power dynamics as a teacher candidate.

I often question whether I'm cut out to be a teacher. I have a passion for teaching and engaging with students, but I often find myself trying to take on more than I can handle, and I worry that it may become a problem in the future.

Lifelong Learner reflects how I feel about the teaching profession in general. I believe the greatest gift of being a teacher is being able to learn from every student that we come across, as well as to share our own knowledge. 
Through the process of collage, I have come to see that hopes and fears are inevitable in the teaching profession, and that we must do our best regardless of our fears.

\section{A Work in Progress by Kaisha Cunningham}
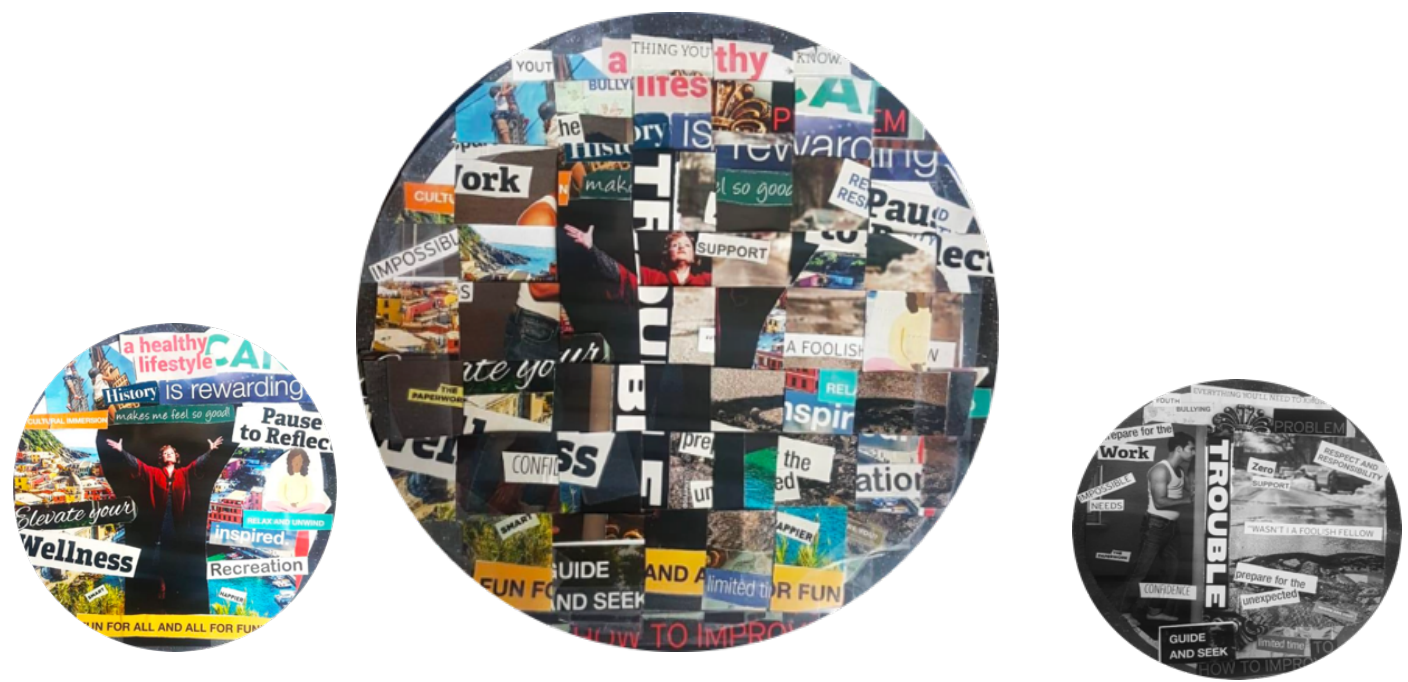

Fig. 7: A Work in Progress collage series by Kaisha Cunningham

Learning can be as... rewarding as climbing a rockwall. It takes a lot of work to gear up and climb, while strategizing each and every move. But at the top of the wall, you feel a great sense of accomplishment and pride. As a teacher candidate, my job is to continue climbing upward, gaining new skills and perspectives until I reach the end of the climb/program.

Learning is like... traveling to a destination you've never been before. You don't truly know what is around the corner, or exactly what it will look or feel like, but the journey is a reward in and of itself. As a teacher candidate, I am doing a lot of traveling to new destinations, and a lot of learning in the process. I have an idea of what to expect, but I am continually surprised inside the classroom at how complex the job is. For some things, I am pleasantly surprised; but for others, I am apprehensive at how I will handle aspects of the job.

As a beginning teacher, I sometimes feel like... I am hitting every pothole on the road. I know that a lot of teaching is based on experience in the field, but I still sometimes feel like I make mistakes that I should have known better. It's difficult not to get down on myself when I am unable to put everything I learned immediately into practice. It will take time for me to be able to incorporate everything I want to into my teaching style.

I often question... If I can do it. Sometimes I feel like I can walk on water, but other times I wonder if I will be as effective a teacher as I hope to be. Because I have ADHD, my organization and sustained mental effort leaves something to be desired. Add to this my impulsivity and childishness, and I wonder how I will ever be the mature adult inside the classroom that is responsible for guiding future generations. I've got a strong case of Impostor Syndrome. 
At times, it can feel like... I am hitting my head against the wall. When things go right, I feel like I can do anything, but when things are not working out the way I intended, I feel frustrated and ineffective.

A Work in Progress reflects... my insecurities about becoming a teacher interwoven with my positive outlook for the future.

Through the process of collage, I have come to see... that as much as I have high expectations for myself, I am still a work in progress, and as such, I should give myself a break every now and again!

\section{Prism of Possibility by Katherine Carranza}
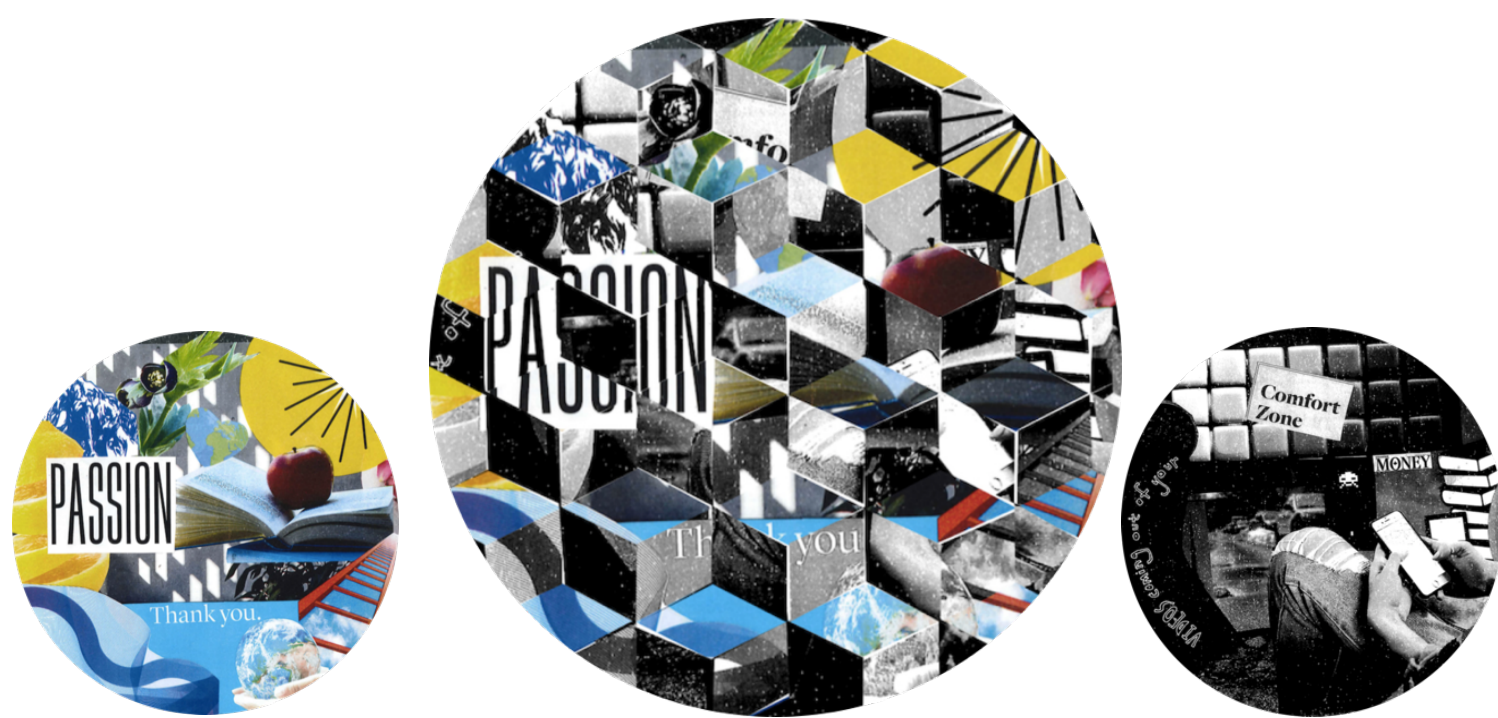

Fig. 8: Prism of Possibility collage series by Katherine Carranza

Learning can be as elementary as going up a ladder, one step at a time. From the moment we open our eyes into this world, we begin learning every day. As an educator, we must understand the individual learning process of our students and how we may scaffold their understanding to ultimately reach success.

Learning is like climbing a mountain. To each, it feels as though their goals are unreachable. I will be diligent in my efforts to always encourage and support my students on their quest for learning. We don't realize until we have reached our destination that the journey was the most amazing part.

As a beginning teacher, I sometimes feel like I am overwhelmed by the responsibility this career holds, but that feeling is quickly replaced with passion. Just as in any other job, teaching comes with its own downsides and stress.

I often question how I can use my own experiences, knowledge, and skills to provide the absolute best possible education for my students. It takes a lot of deep reflection to identify the qualities of both good and bad teachers that I have had, and even more effort in understanding how different each learner really 
is-what worked for me may or may not work for them, and I have to learn how to be consciously versatile.

Prism of Possibility reflects that with everything in life, you have to take the good with the bad. It won't always be sunshine and flowers as in the hope collage, nor will it always be challenges depicted in the fear collage. Once we shine our light of insight, it all comes together to form a bigger picture with a bigger meaning of being versatile.

\section{Flipping Through Hope \& Doubt by Krista Deda}
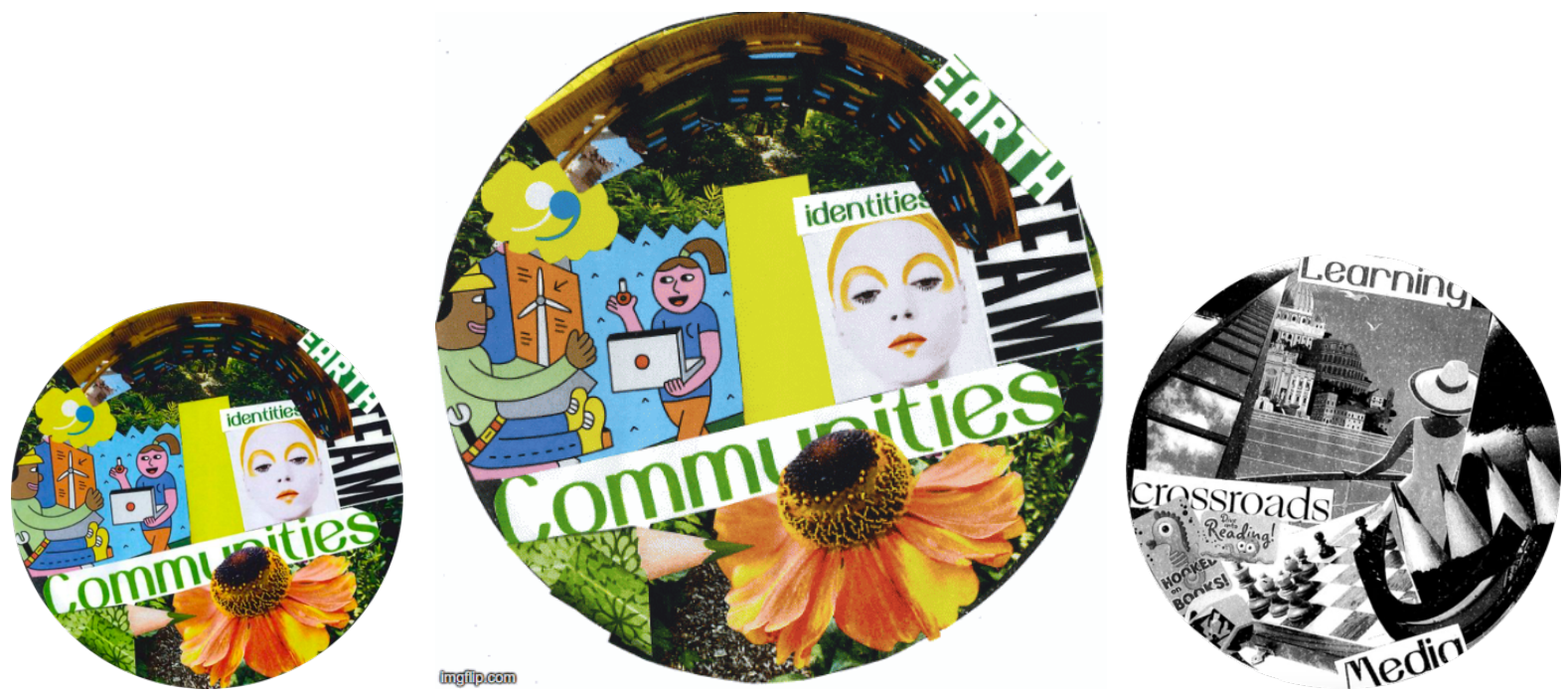

Fig. 9: Flipping Through Hope \& Doubt collage series by Krista Deda

Learning can be a rollercoaster of the most rewarding feelings by working collaboratively with peers, students, and community. Most importantly in our current society, the enforcement of equity in our classroom is crucial. Quotation marks in my hope collage represent the importance of embracing student voice, opinion, interests, cultures, and ethnicities, combining a positive, successful, and inclusive environment for students, allowing them to embrace and motivate their learning.

Learning is like a flower blossoming, a pathway and journey. Some flowers blossom quickly, some take their time, some blossom and close again; they are all on different journeys of growth. Likewise, with students, who are all in different pathways of learning in education. All students have different methods of learning, such as visual, kinesthetic, auditory, and intrapersonal. Learning is a journey that is different for all. Educators need to acknowledge this, and be willing to learn from their peers, their students, and themselves.

As a beginning teacher, I sometimes feel like I have so much to learn. Although what I have realized and now believe, is that being an educator is a lifelong journey of learning. Like the journey of travel, since there is constant discovery, seeing and cruising. Educators are in constant learning of applying great 
modifications and accommodations, enforcing inclusion, and belonging in the classroom through their lesson design and plan.

At times, it can feel like climbing a ladder. As I climb the ladder of my future as an educator, I hold great responsibility of being the best role model for students. I want to continue climbing in order to support, guide, and encourage student learning and success.

I often question how much I will know my students, and how much I will implement my knowledge about them in my program, my lesson design and plan? I connect this to the game of chess, as you may know the roles of each chess piece. Although you may underestimate its powers or not comprehend the impact of their roles and actions.

"Flipping through hope and doubt" reflects my excitement towards my future as an educator. Although I have my feelings and opinions of both hope and doubt, as I flip through my images and photos formed together, I realize they contain the colourful world of my opinions, perspective, and beliefs as an educator.

Through the process of collage, I have come to see that my hopes and doubts intertwine. Going into this activity, I knew I had my opinions as an educator, although I wanted to embrace my fears and doubts. I wanted both my collages to be colourful, since my beliefs as an educator are a reality of colour! For the purpose of creating my GIF, I made my hope in colour and doubt in black and white in order to differentiate the two. Although my doubt collage is just as colourful as my hope, I wanted to express my willingness and dedication to overcome future obstacles. I want to make sure I embrace students' differences and unite them for a learning experience for myself, students, and their peers.

\section{Common Unities: Moments, Maps \& Memories by Sabriyya Bacchus}

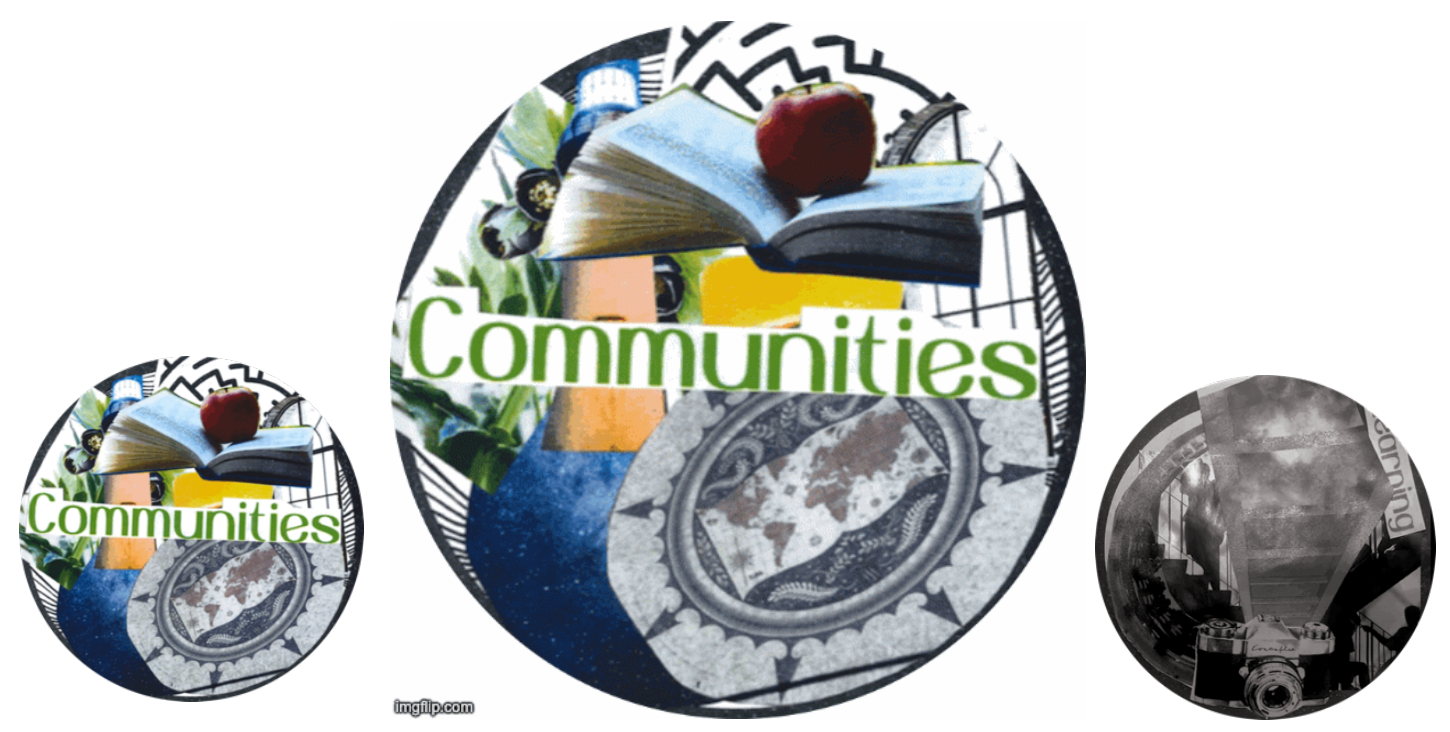

Fig. 10: Common Unities: Moments, Maps \& Memories collage series by Sabriyya Bacchus 
Learning can be fluid; done in any location, by any one, from any walk of life. This is why I included different light sources and locations throughout both collages, to represent the transferability of learning, but also to remind myself that enlightenment is not limited to any place (and neither is learning). I'm mindful as a youth worker and teacher candidate that my students (much like my own youth) come from all walks of life, and with them they bring their lived experiences, past and present.

Learning is linear for some and a rollercoaster for others. It is an ongoing process, and without a doubt, the sky is the limit. Learning also takes place in many different forms - in nature, in our communities, through books, and through the stories we tell one another. As an aspiring teacher, it can be nervewracking to think that I will be responsible for the learning experiences of so many students, some of whom have not had prior experiences with learning that have been positive. I am reminded of my roots, of going to inner-city schools with friends whose parents (unlike my own) didn't prioritize school sometimes because just surviving in Toronto was all they had the energy for. I am also reminded that I continue to learn every day, from my own life, but more importantly from the lives of those around me.

As a beginning teacher, I sometimes feel like I don't belong here. My experience at York has been adverse. I started the year off less than a month after my uncle died unexpectedly. Since I worked full time all summer, and of course needed my pay to put towards my tuition, there was never really a moment to stop and process my loss. This loss came after a turbulent summer as well, and I spent first semester working seven days a week to make sure my winter tuition would be paid. In contrast, I feel a disconnect from many of my peers who seem to only have school as a priority, and more immersed in the academic experience than I have the capacity to be. I'm grateful to my mentor teacher who inspires me to finish this program despite often wondering why I started it...

At times, it can feel like I'm on a never-ending staircase or navigating using only a map (I'm definitely directionally challenged and would not have survived before GPS). I have learned not to focus too much on one thing to avoid becoming overwhelmed by others. Rather than look back one day and wish I had valued this experience more, I try to be present in the parts of it I am enjoying and chalk up the parts that $\mathrm{I}$ 'm not to life just being that way sometimes.

I often question where in this field I will actually end up; my roots are as a child and youth worker and that's definitely where my heart is. I've worked in recreation since I was 16 and it remains one of the most transformative experiences of my life. I also aspire to work internationally, whether in community development, youth work, or education. In the last year, I have also taken on some of the responsibilities associated with managing my best friend's career as an artist; and building his brand is the ultimate learning experience. Over time, I have learned that teaching is not limited to just the classroom, or the typical students and teacher experience. So, whether I end up planning tours and music festivals for the rest of my life or with an LTO position right out of teacher's college, I'm open to where my path takes me.

"Common Unities" reflects how my doubts and hopes exist synonymously; there were aspects of both images in each collage. My initial (hope) collage was entitled, "Spaces and Places," and more 
representative of the different realms that learning takes place in. My second (doubt) collage was entitled, "The Climb," and meant to represent the different routes individuals take on their learning journeys. Ultimately, I believe in the universality of the learning experience, and that as a teacher, I hope to promote diverse learning experiences.

Through the process of collage, I have come to see that reflection is not limited to words and often more effective when done in a visual format. I was sceptical about this assignment to begin with, but am ultimately proud of my final product as I think it is representative of my learning journey this year.

\section{From the Outside Looking In By Yann Myslowski}

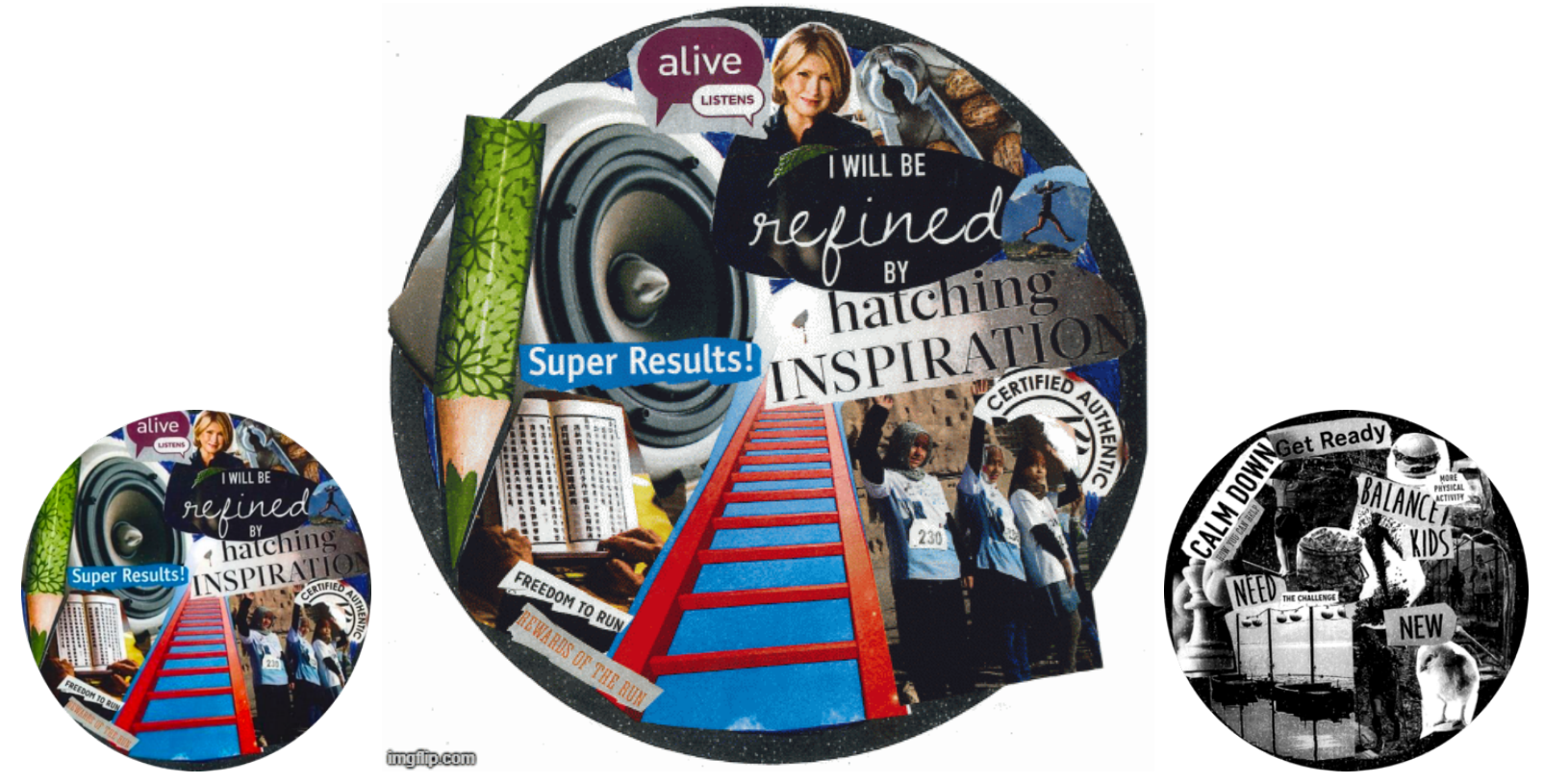

Fig. 11: From the Outside Looking In collage series by Yann Myslowski

Learning can be as easy as listening, reading, and writing, but can also be as hard as climbing a fence, hiking a mountain, or walking a tightrope. From the outside looking in, learning can be like a perfect balance of uncertainty and inspiration. As a future educator, I'm uncertain about what subjects and grade levels I will end up teaching, but I'm equally inspired by the sheer amount of learning both my students and I will be doing together along the way.

Learning is like climbing a seemingly never-ending ladder toward the infinitely open skies of self-actualization and greatness. Learning is like steadily growing in strength, by climbing one rung of the ladder at a time, until you are strong enough to crack through the shells of doubt, thus hatching inspiration for you and everyone you've climbed with. As a future teacher, I want my students to find comfort in knowing that we are all in this journey of learning together. 
As a beginning teacher, I sometimes feel like a freshly born chick, hatched from a shell of comfort and certainty, and hesitant to take my first steps up the hill of learning. I sometimes feel like I won't know what I'm doing in my first years of teaching, but I am comforted by knowing I've experienced feelings of doubt before, and I have always overcome my perceived adversities by listening to the wisdom of those who have gone through the journey before.

I often question whether I'Il be able to provide my future students with the ideal balance of challenge, inspiration, and authenticity during our shared learning episodes in the classroom. I also question how I will know whether I've truly helped my students succeed at making the most of their strengths, other than via standardized assessment methods.

"From the Outside Looking In" reflects how I feel about currently being nothing more than a first-year teacher candidate overflooded with ambitious and morally applaudable ideologies of universal inclusiveness for my future students. I feel uncertainty as to whether I'Il be able to transform my goodhearted ideologies into actual and effective teaching practices.

Through the process of collage, I have come to see how learning is about creating your own meanings from all the physical and abstract symbols we are surrounded by in our daily environments. Prior to constructing my collages, I had no plan in mind and had no idea what I would create. Once completed, my collages gave me new meanings of hope and doubt.

\section{Lessons Learned Through Collage: Students' Perspectives}

These six students' collages and statements illustrate how collaging offers teacher candidates an invitation to engage in alternative ways of knowing and seeing and provides a structure to scaffold reflection. With the support of the creative, visual process of collaging, students then approach writing a personal statement with figurative language that reveals their embodied experiences.

I had originally planned for students to share their collages with one another in a gallery walk during our final class. Because we had to wrap up the semester online, I asked students to complete a brief "exit-ticket" by responding to the question: How did you engage with the experience of reflecting through collage as a teacher candidate? How did collage support or constrain your reflection? Students' answers were quite revealing.

Pat expressed that his collage

revealed thoughts and feelings about teaching that I haven't necessarily addressed or dealt with throughout the academic year. I think that the busy lifestyle of teacher's college doesn't always give us the opportunity to reflect on our overall experience or our anxieties about the future.

For Katherine, the practice of collaging

reminded me that there is more to reflection than a post on Moodle [LMS], and that these exercises are incredibly valuable to see a picture of our inner self. My collage encouraged me to be more openly perceptive of my work, to explore my creativity, and to acknowledge the very 
real fear and anxieties that I have for my future in this profession. I found that I have been so preoccupied with the stress of life that I subconsciously stopped looking for meaning in the little things of life, and this assignment opened my eyes to the symbolism we can find.

Both students point to the pace of their teacher education program being at odds with inner reflection. They welcomed the time and space to engage in creative reflection.

For other students, however, the initial response to the invitation to engage in reflection through collage was not so enthusiastic. For example, Sabriyya and Yann noted that they were skeptical at first because they didn't see themselves as "artistically inclined." Kaisha went further to explain that for her,

At first, I thought the assignment was silly and infantilizing, but after I started working on it, I began to see the benefit. There have been ways that I have been feeling that have been difficult for me to put into words, but this activity has afforded me the opportunity to engage with those feelings in a concise and constructive way. Collage supported my reflection in particular by giving me the ability to put my innermost reflections into metaphoric pictures.

While all three students engaged at first with some reluctance, by entering into the scaffolded experience, they came away with new insights about themselves and the power of opening up to alternative ways of knowing.

Yann went on to elaborate how, ultimately, the entire experience of collaging and then crafting his personal statement, allowed him to come to a deeper awareness of self:

I have always been a self-proclaimed math and science advocat[e], claiming there is far more value in knowing the objective truths of reality than there is in learning about mine or other people's subjective interpretation of reality. However, engaging in every stage of this collage-making experience, from the initial planning process of deciding what types of visual media I would bring to class, to the actual collage construction process, to reflecting on the meanings evoked from my final collage products, has reminded me that learning is more about the process of struggling through challenges, than it is about being provided with new knowledge. It was via the entire process of creating my collages, rather than simply seeing the result, that I was able to develop new meanings about myself with respect to my hopes and doubts of becoming a teacher.

After going through this rare... experience of creating self-defining collages, the process of making my collages and writing accompanying personal statements has provided me with fresh insight into ways of thinking about my reasons and goals for becoming a teacher. I entered the process with initial beliefs about myself and my potential for being a teacher, but I only knew how to conceive and describe these beliefs in ways I was familiar and comfortable with. As I engaged in the collage-creation process, I developed alternative ways of thinking about the learning process in general, and how learning can and should occur in a variety of different forms in order to create a variety of meanings.

Yann's description of the experience of collaging as "rare" reveals that depending on their disciplinary backgrounds, teacher candidates may not have equally had exposure to the use of alternative modes of representation and expression to scaffold their reflection and meaning making. In such cases, the need for aesthetic-based pedagogies in teacher education is all the more critical. 
Krista also explained that for her,

through this process of forming my personal thoughts, through searching and cutting symbols, and forming them together, I surprisingly have a more clear view, understanding, and hope as a future educator pursuing to be and reflect on everything I have learned throughout this course...the process of creating a collage and writing an accompanying statement makes space for students to further understand themselves."

Similarly, Sabriyya notes that

the collaging process helped to support my reflection as it allowed for imagery and metaphor to play a part in the reflective process, and also allowed for my personal statement to incorporate more creative writing than can be typically used in reflection pieces at the university level.

While there is no magic in collaging as reflection, the examples of practice and students' perspectives in this article provide an empirical base to support further exploration of aesthetic-based pedagogies in preservice teacher education. Indeed, making space to listen to our inner selves can support teacher candidates in bringing their whole selves into their teaching and learning and inviting their students to do the same.

\section{References}

Butler-Kisber, L. (2010). Qualitative inquiry: Thematic, narrative and arts-informed perspectives. SAGE.

Butler-Kisber, L. (2018). Qualitative inquiry: Thematic, narrative and arts-based perspectives. SAGE.

Bresler, L. (2018). Aesthetic-based research as pedagogy: the interplay of knowing and unknowing toward expanded-seeing. In Leavy, P. (Ed.). Handbook of arts-based research. Guilford Publications.

Cahnmann-Taylor, M., \& Siegesmund, R. (Eds.). (2017). Arts-based research in education: Foundations for practice. Routledge.

Cole, A. L., \& Knowles, J. G. (2008). Arts-informed research. Handbook of the Arts in Qualitative Research, 55-70.

Csikszentmihalyi, M. (1975). Beyond boredom and anxiety: Experiencing flow in work and play. Basic Books.

Dewey, J. (1933). How we think: A restatement of the relation of reflective thinking to the educative process (Vol. 8). DC Heath and Company.

Prasad, G. L. (2015). The prism of children's plurilingualism: A multi-site inquiry with children as co-researchers across English and French Schools in Toronto and Montpellier (Doctoral dissertation). http://hdl.handle.net/1807/71458

Robinson, A. H. (2013). Arts integration and the success of disadvantaged students: A research evaluation. Arts Education Policy Review, 114(4), 191-204. 
Schön, D. A. (1983). Reflective practitioner (Vol. 5126). Basic Books.

Wiebe, S., Sameshima, P., Irwin, R., Leggo, C., Gouzouasis, P., \& Grauer, K. (2007). Re-imagining arts integration: Rhizomatic relations of the everyday. The Journal of Educational Thought (JET)/Revue de La Pensée Éducative, 263-280.

Zeichner, K., \& Lui K. Y. (2010). A critical analysis of reflection as a goal for teacher education. In Lyons, N. (Ed.), Handbook of reflection and reflective inquiry (pp. 67-84). Springer.

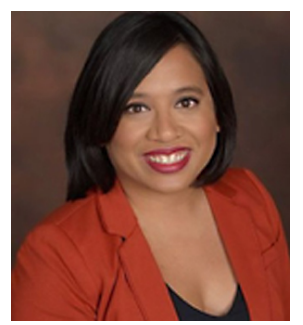

Gail Prasad is an Assistant Professor in the Faculty of Education at York University, Toronto, Canada. Her research focuses on children's and teachers' social representations of plurilingualism, critical multilingual language awareness, and approaches to multilingual teaching and learning. She brings her training in applied linguistics and education together with her interest in the arts through her use of arts-based approaches in her research and teaching. Her work has been published in English and in French in journals including TESOL Quarterly, Language and Intercultural Communication, International Journal of Bilingual Education, Bilingualism, and Glottopol.

The Lions BEd Group is made up of six teacher candidates at York University who were enrolled in the course "Inquiries into Learning" with Professor Prasad during the 2019-2020 academic year. They each contributed their final collages and reflections to this article. Pat Baybayan, Kaisha Cunningham,

Katherine Carranza, Krista Deda, Sabriyya Bacchus, and Yann Myslowski are pursuing teacher certification in the junior and intermediate division with various subject specialities. Each of the members of the Lions BEd Group are eagerly looking forward to joining and advancing the field of teaching and learning through their reflexive practice. 